\title{
Do IMF-Supported Programs Boost Private Capital Inflows? The Role of Program Size and Policy Adjustment
}

Roberto Benelli 


\title{
IMF Working Paper
}

\section{Research Department \\ Do IMF-Supported Programs Boost Private Capital Inflows? The Role of Program Size and Policy Adjustment}

\author{
Prepared by Roberto Benelli ${ }^{1}$ \\ Authorized for distribution by Eduardo Borensztein
}

November 2003

\begin{abstract}
The views expressed in this Working Paper are those of the author(s) and do not necessarily represent those of the IMF or IMF policy. Working Papers describe research in progress by the author(s) and are published to elicit comments and to further debate.
\end{abstract}

I analyze empirically whether program size (the size of financial assistance) and policy adjustment matter for the success of IMF-supported programs. I define a program as successful if the initial program projections for net private capital flows are met or exceeded. I find that success is negatively associated with the size of financial assistance, especially in countries with market access, and that projection biases binding constraints on the amount of IMF lending may account for this association. Moreover, policy adjustment seems to have a causal positive effect on the likelihood of program success.

JEL Classification Numbers: F33, F34, F41

Keywords: Success of IMF programs; policy adjustment under programs

Author's E-Mail Address: rbenelli@imf.org

\footnotetext{
${ }^{1}$ I am very grateful to Eduardo Borenzstein, Peter Clark, Carlo Cottarelli, Olivier Jeanne, Gian Maria Milesi-Ferretti, Ashoka Mody, Alex Mourmouras, Alessandro Prati, Rodney Ramcharan, Roberto Rigobon, Jeronimo Zettelmeyer, and especially Paolo Mauro and Alessandro Rebucci for helpful discussions and comments. All remaining errors are mine.
} 


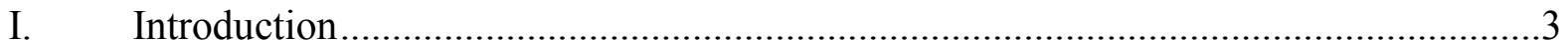

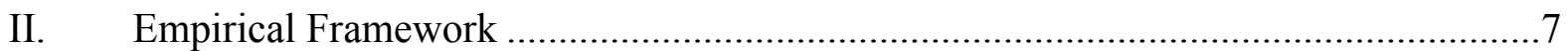

A. Data Sources .........................................................................................

B. Why Use the Shortfalls in Net Private Capital Flows? ........................................

III. Are the Shortfalls in Net Private Capital Flows Random Errors? ............................... 9

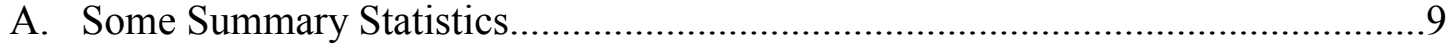

B. A Simple Test of Projection Efficiency ............................................................13

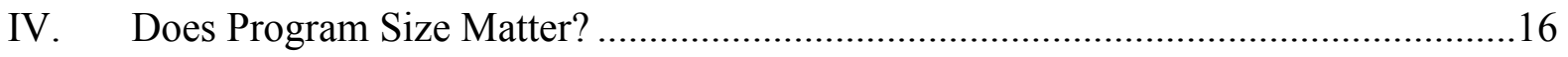

V. How do Capital Flows Respond to Policy Adjustment?...........................................22

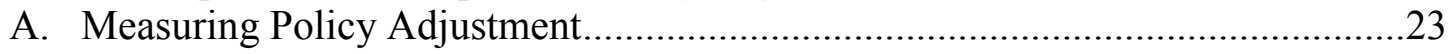

B. Association Between Policy Adjustment and Capital Flows ...............................24

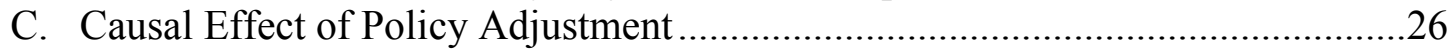

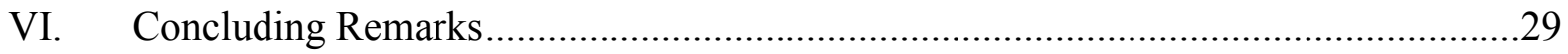

Tables

1. Summary Statistics of Projections and Shortfalls in Net Private Capital Flows by Type of Program and External Source of Financing.............................................12

2. Test of Projection Efficiency.......................................................................... 15

3. Summary Statistics of Program Access............................................................... 18

4. Shortfalls and Program Access.............................................................................. 19

5. Association between Shortfalls and Policy Adjustment for Nonprecautionary

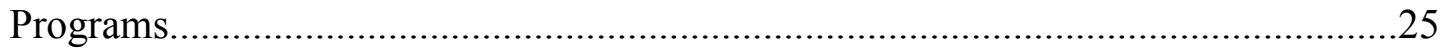

6. Causal Effect of Policy Adjustment for Nonprecautionary Programs.......................27

Appendix Table

A.1. Bias in Structural Estimates Owing to Projection Biases........................................31

Figures

1. Distribution of Shortfalls in Year1 for All Program............................................10

2. Projected and Actual Net Private Capital Flows for All Programs...........................14

Appendix

I. Consequences of Biased Projections for Instrument Validity................................30

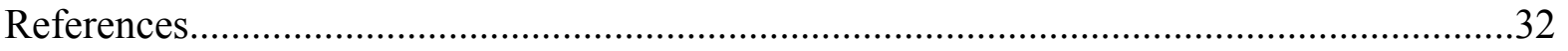




\section{INTRODUCTION}

What determines the success of International Monetary Fund (IMF)-supported programs? A simple approach is to ask whether the financing that a country can raise from private sources meets or exceeds the target set by the program. Among the many criteria, this is particularly relevant, because restoring capital market access is necessary for program viability when programs can provide only a fraction of a country's overall external financing need and, as a result, have to rely on private sources to help cover the remainder. Therefore, in this paper, I will define a program to be successful if net private capital flows do not fall short of their projections.

The purpose of this study is to analyze what determines program success. At a stylized level, a program consists of financial assistance-whose magnitude is often referred to as the "size of the program"- - and policy adjustment; thus, it is worth asking whether these two components contribute to success. Theory does not permit one to make clear predictions on whether larger programs are more likely to succeed. On the one hand, a larger financial commitment may, for example, improve the IMF's incentives for better monitoring and program design, thereby generating a positive response from private investors (see Rodrik, 1996). On the other hand, IMF programs may encourage capital outflows by providing much-needed foreign currency reserves. Likewise, how policy adjustment affects capital flows is unclear in principle. Tight macroeconomic policies are usually considered desirable to restore investor confidence and encourage the return of private capital. However, critics of the IMF programs during the Asian crisis in 1997 have seriously questioned that view (see Furlam and Stiglitz, 1998).

Besides being straightforward, this approach has four advantages. First, by using program projections for net private capital flows as a benchmark for actual flows, I avoid the problem of defining a "counterfactual" scenario (what would have happened without a program) against which to define program success. Since programs contain projections for capital flows, each program itelf provides the relevant benchmark for actual flows, and no counterfactual needs to constructed.

Second, this approach allows me to deal directly with the implications of the requirement, mandated by the IMF's Articles of Agreement, that financial assistance be provided only in the presence of a proven balance of payments need. As a result of this requirement, programs typically aim at improving the current account balance; in fact, one of the most robust and less controversial findings in the literature on the effects of IMF programs is that the current account balance improves under IMF programs (see Haque and Khan, 1998). In turn, improving the current account tends to lower the country's demand for external sources of finance. Thus, one has to be careful not to confuse the reduction in net capital inflows owing 
to the external adjustment with the failure to generate private flows. Comparing net capital flows against a program-dependent benchmark eliminates any potential confusion. ${ }^{2}$

Third, this approach allows me to measure the strength (or weakness) of the "catalytic" effects of IMF lending. Although programs, particularly during the capital account crises of the 1990s, may have been designed to catalyze private capitals - that is, spur private capital inflows - the empirical evidence of catalytic effects is weak (see Cottarelli and Giannini, 2002). A direct way to assess catalytic effects is to ask whether the programs generate the net capital flows that have been projected by the IMF at the stage of program design. In this light, a shortfall in actual flows relative to these projections shows that the factors that should have generated catalytic effects have not played the expected role.

Fourth, this approach allows me to estimate how policy adjustment affects program success by isolating the causal effect of policy adjustment from its endogenous response to external shocks. The endogeneity problem arises because, for example, tight monetary and fiscal policies may not be sustainable if an exogenously determined, unexpected worsening in capital inflows causes a deep recession. Addressing this endogeneity problem requires valid instruments for the policy adjustment that takes place under the program. I use the projected policy adjustment - the change in inflation and the change in fiscal balance - as an instrument for the actual policy adjustment. The projected policy adjustment should meet the two requirements of a valid instrument: the projections should be correlated with what actually happened and not be correlated with the capital account shocks that occur during the program. $^{3}$

The quality of the macroeconomic data for the sample considered here is not always high. This implies that clear and robust empirical regularities are unlikely to emerge and that all results have to be interpreted with caution. Nevertheless, the empirical evidence presented in this paper seems to provide a consistent picture of the effects of IMF programs. The first main finding is that program success does not seem to be a purely a random event; in particular, success is negatively associated with the size of financial assistance, especially in countries with access to private capital markets. Although this finding could mean that larger programs cause capital outflows, this causal interpretation is somewhat ambiguous, because I find some evidence that biases in projections for net private capital flows may account for the negative association between success and program size. These biases might be caused by

\footnotetext{
${ }^{2}$ The current account could improve more than projected because of an unpredictable exogenous shock such as, for example, an improvement in terms of trade, thus reducing the need for capital flows. Although in this case my approach signals a "failure", there will be no consequence for the unbiasedness of the econometric estimates of the effect of programs. This is discussed in more detail in Section II.

${ }^{3}$ One problem with this empirical strategy is that the instrumental-variable estimate of the causal effect of policy adjustment is inconsistent if the program projections are biased. However, the magnitude of this bias can be quantified and turns out to be fairly small.
} 
the fact that the IMF's limited resources constrain the amount that can be lent in a program, especially when this amount is large (in relative terms). When these constraints are binding or close to being binding, the IMF staff is more likely to feel pressures to generate relatively more optimistic projections to cover any residual financing gap that cannot be covered by additional program lending. Since this optimism is likely to be larger in larger programs, it could explain why shortfalls in net private capital flows are more likely to occur in larger programs.

The second main finding is that policy adjustment, especially in monetary policy, contributes to program success. Although it is not possible to estimate the causal effect precisely, it is, as expected, considerably smaller than the ordinary-least-squares estimate - that is, the estimate that is computed without correcting for policy endogeneity. This finding therefore suggests that, in countries with market access, exogenous capital account shocks are very important determinants of what policy adjustment the domestic authorities can undertake.

The remainder of this section reviews some related literature. Section II presents the main data source and the empirical framework used in the paper. Section III provides some basic stylized facts about main object of interest of the paper, the shortfalls in net private capital flows, and a simple test of projection efficiency. Sections IV and V study whether financial assistance and policy adjustment, respectively, matter for program success. Section VI provides conclusions and is followed by an appendix.

The empirical literature on the effects of IMF programs is large and growing; here, I will review only a few papers on the effects of programs on capital flows. ${ }^{4}$ Several papers have studied the catalytic effects of IMF programs - that is, the validity of the hypothesis that a program can restore the confidence of the international investors and thus spur private capital inflows. After thoroughly reviewing the literature, Cottarelli and Giannini (2002) and Bird and Rowlands (2002) conclude that the evidence of catalytic effects is weak. Ghosh and others (2002) reach similar conclusions in the context of the capital account crises that occurred during the 1990s.

Most of the literature does not take into account the potential bias that can result from the fact that adjusting the current account tends to lower the demand for net private capital inflows. For example, Rodrik (1996) studies the effect of past net bilateral and multilateral transfers on net private capital flows by regressing the latter on the former and finds that the effect of IMF lending is either not significantly different from zero or negative; Bird and Rowlands (1997) reach similar conclusions using an analogous approach. Mody and Saravia (2003) look at gross capital inflows (specifically, new bond issues) to avoid confusing the

\footnotetext{
${ }^{4} \mathrm{~A}$ recent example of the more general literature on the effects of Fund programs is Barro and Lee (2002). See Haque and Khan (1998) and Krueger (1998) for surveys of earlier studies on the effects of Fund programs, and Ramcharan (2003) for a recent survey. There is also an abundant literature on the moral hazard implications of IMF programs; see Dell'Ariccia, Schnabel, and Zettelmeyer (2002) and the references therein.
} 
program-induced external adjustment with the lack of catalytic effects, because, if programs have a positive effect on investor confidence, one should observe more issues at better terms. It is not entirely clear, however, how a change in the net demand for external funds translates into a change in gross flows. Similar conceptual difficulties affect those papers that focus on specific asset classes or investment decisions, such as debt restructuring (Marchesi, 2003) or foreign direct investment (Edwards, 2000); moreover, it is difficult to gauge the macroeconomic relevance of findings based on individual asset classes. ${ }^{5}$ Since program projections for net private capital flows have, in principle, to take the current account adjustment into account, my definition of program success is not subject to this problem.

Little empirical research has been devoted to the effect of program size. An exception is the paper by Mody and Saravia (2003), which finds that larger programs help raise the probability of issuing new bonds at a lower spread. My paper sheds light on the effect of size by studying whether size has a systematic relationship with the shortfall in net private capital flows.

Most of the literature does not take into account the fact that policy adjustment is endogenous - in spite of playing a central role in the programs, policy adjustment is often not taken into account at all. One approach that does attempt to control for macroeconomic policies is the Generalized Evaluation Estimator (GEE) discussed in Haque and Khan (1998) and recently applied by, among others, Dicks-Mireaux and others (2000) and Bulír and Moon (2003). This approach attempts to estimate the economic policies that would have been in place in the absence of the program; these policy counterfactuals are then introduced as a control variable in the equation for the variable of interest, such as GDP growth. Because it uses policy counterfactuals rather than the actual policies followed under the program, the GEE approach does not have much to say about the effect of actual adjustment - in contrast to this paper. The approach of this paper is close to the one followed by Musso and Phillips (2001), which analyzes the effect of actual program implementation on programs' projection errors. However, these authors do not take into account the fact that program implementation is likely to be endogenous. To control for policy endogeneity, I use the projected adjustment as an instrument for actual adjustment; a similar approach has been used by Berg and others (1999). ${ }^{6}$

\footnotetext{
${ }^{5}$ This bias is likely to be less severe in those papers that analyze how interest rate spreads respond to programs, such as Eichengreen and Mody (2000) and Mody and Saravia (2003). ${ }^{6}$ Finally, there are a few related studies on the consequences of tight monetary policy during the Asian crisis (see, for example, Basurto and Ghosh, 2000). This literature is related to a more general strand that studies the effect of monetary policy on speculative attacks (see, for example, Kraay, 2003). Its focus, however, is not on the systematic effects of policy adjustment under IMF programs.
} 


\section{EMPIRICAL FRAMEWORK}

In this section, I first present the main source of the data used in the paper and then discuss the empirical framework that underpins the analysis of the following sections.

\section{A. Data Sources}

The main source is the Monitoring of IMF Arrangements (MONA) database, maintained by the IMF's Policy Development and Review Department. I study the stand-by and extended arrangements that are included in MONA from its inception in 1992 through 2001. These are the arrangements used by the IMF for its ordinary, non-concessional lending activity; in the following, I refer to them as "programs". The sample contains 136 programs, 105 stand-by arrangements and 31 extended arrangements. ${ }^{7}$

I construct a residual measure of net private capital flows (henceforth, NKF) by subtracting from the overall balance the current account balance, official transfers, and official multilateral and bilateral borrowing. This measure of net private capital flows corresponds to the sum of the financial account balance and net errors and omissions in the Fifth Edition of the Balance of Payments Manual (IMF, 1993). ${ }^{8}$ Using the information available at the start and conclusion of the program (or last available review), I construct measures of the initial program projections for and actual realizations of net private capital flows. For cross country comparability, I scale the net private capital flows by the gross domestic product, also provided by MONA.

The choice of timing is delicate. For example, I could compare the projections and the realizations during the calendar year the program is approved, which I refer to as year $\mathrm{T}$. However, this comparison would confuse the pre-program developments with the response to the program. Therefore, I choose to compare the projections and outcomes in year $\mathrm{T}+1 .{ }^{9}$ As a result, the very short term response of net private capital flows is not considered.

\footnotetext{
${ }^{7}$ MONA includes only three programs started in 1992. The actual number of programs used in the empirical analysis below will vary depending on data availability.

${ }^{8}$ My definition of net private capital flows corresponds to the sum of the financial account and net errors and omissions except for any transfer and borrowing from multilateral and bilateral entities that are included in the financial account. This definition implicitly assumes that net errors and omissions are financial account transactions. Since MONA does not provide disaggregated information on private capital flows by category, only an aggregate measure of net private capital flows can be constructed.

${ }^{9}$ Because of data constraints - my dataset is annual-I cannot control for the exact timing of program approval. For example, I am unable to control for the fact that projections for year $\mathrm{T}+1$ in a program approved toward the end of the calendar year are likely to be less accurate than projections for year $\mathrm{T}+1$ in a program approved at the beginning of the year.
} 
The basic unit of observation is an individual program. Treating each program as a distinct episode raises thorny conceptual difficulties because many country have multiple programs over the sample period. Furthermore, many changes can intervene during the program, for example, in its length or size, possibly altering its initial characteristics substantially. This problem, discussed in more detail below, is particularly relevant with regard to program size.

Finally, I use the World Economic Outlook database for series on PPP-adjusted gross domestic product and the stock of external liabilities (PPPWGT and D, respectively).

\section{B. Why Use the Shortfalls in Net Private Capital Flows?}

Suppose that the net private capital flows (denoted by $k$ ) to a country over a certain period following the adoption of a program are governed by the following equation:

$$
k=\alpha+k_{0}+\beta P+\varepsilon,
$$

where $\alpha$ is a constant term; $k_{0}$ is a term that captures the effect on capital flows of initial conditions; $P$ is a vector of program variables, e.g., policy adjustment and size of financial assistance; $\mathcal{E}$ is an unobserved shock; $\beta$ is a vector of coefficients on program variables. In this framework, the signs and magnitudes of the coefficients in $\beta$ determine whether and to what extent program variables help generate capital flows. Besides program variables, net private capital inflows respond to exogenous shocks, captured by the term $\mathcal{E}$. Examples of exogenous shocks are changes in the terms of trade, unexpected rises in export production, or changes in interest rates in advanced countries. As these shocks are, by definition, uncorrelated with the right-hand side variables in the regression, there will be no bias in the estimated coefficients.

Many problems in empirically evaluating the effects of IMF programs stem from the fact that the econometrician cannot observe precisely the program's initial conditions, i.e., the term $k_{0}$ in (1). For example, countries are likely to start programs when they face serious economic difficulties, i.e., when the term $k_{0}$ is "unusually" low. Since the program characteristics, such as the size of financial assistance and policy adjustment, are likely to be negatively correlated with $k_{0}$-because the larger the initial economic difficulties, the larger the financial assistance and policy adjustment — then ignoring $k_{0}$ when estimating (1) produces inconsistent estimates of $\beta$.

The approach based on explicitly modeling the selection of countries into programs (see, e.g., Edwards (2000) and Przeworski and Vreeland (2000)) aims at inserting an omitted variable, into an outcome equation such as (1). Intuitively, this approach compares program countries with countries without programs to estimate the probability of starting a program. This information is then used to construct a variable (the inverse Mills ratio), which plays the role of $k_{0}$ in (1), that corrects for the omitted variable bias due to self-selection. Having corrected 
for the self-selection problem, the econometrician can consistently estimate $\beta$ and thus infer the effects of program variables on private capital flows.

In addition to the self-selection problem, $k_{0}$ is also related to the size of external adjustment that the country is to undertake under the program. For example, suppose that the program requires that a country considerably reduce its current account deficit. This adjustment would also reduce the demand for net private capital flows, in turn implying a smaller value for $k_{0}$. Since the magnitude of the expected external adjustment is likely to be positively correlated with program variables, then the omission of $k_{0}$ would bias the estimate of $\beta$.

Rather than constructing $k_{0}$, I use the projections for net private capital flows made by the IMF at the beginning of the program. Using projections to control for the initial conditions has two main advantages. First, I avoid the complications of explicitly modeling the selection into IMF programs. Second, I indirectly take into account the size and nature of the shocks that lead to the program; since these shocks should in principle be taken into account by the IMF staff "on the ground" when formulating their projections, they are included in the estimated equation. The main assumption underlying this approach is that the projections are formulated within a uniform and consistent framework across programs. ${ }^{10}$

Finally, to highlight that the shortfall in net private capital flows relative to their projections is my measure of program success, I rearrange equation (1) to work with the shortfall $\bar{k}-k$ as my dependent variable.

\section{Are the Shortfalls in Net Private Capital Flows Random Errors?}

This section firsts documents some basic facts about the projections for net private capital flows and their shortfalls and then provides a simple test of projection efficiency.

\section{A. Some Summary Statistics}

Figure 1 plots the distribution of the main object of interest, the shortfall in net private capital flows in year $\mathrm{T}+1$ of the program, defined throughout the paper as the difference between projected and actual net private capital flows in percent of GDP. Although the distribution of the shortfalls appears to be fairly symmetric, it is centered below zero, i.e., the projections

\footnotetext{
${ }^{10}$ It is also worth noting that the exchange rate regime does not affect the notion of program success. The exchange rate regime is likely to affect what happens when actual flows differ from their projections but not whether a country receives as much capital as projected at the start of the program. For example, if net private capital flows exceed their projections, foreign reserve accumulation will be accumulated in a fixed exchange rate regime and the exchange rate will appreciate in a pure float.
} 
Figure 1: The Distribution of Shortfalls in Year 1 for All Programs

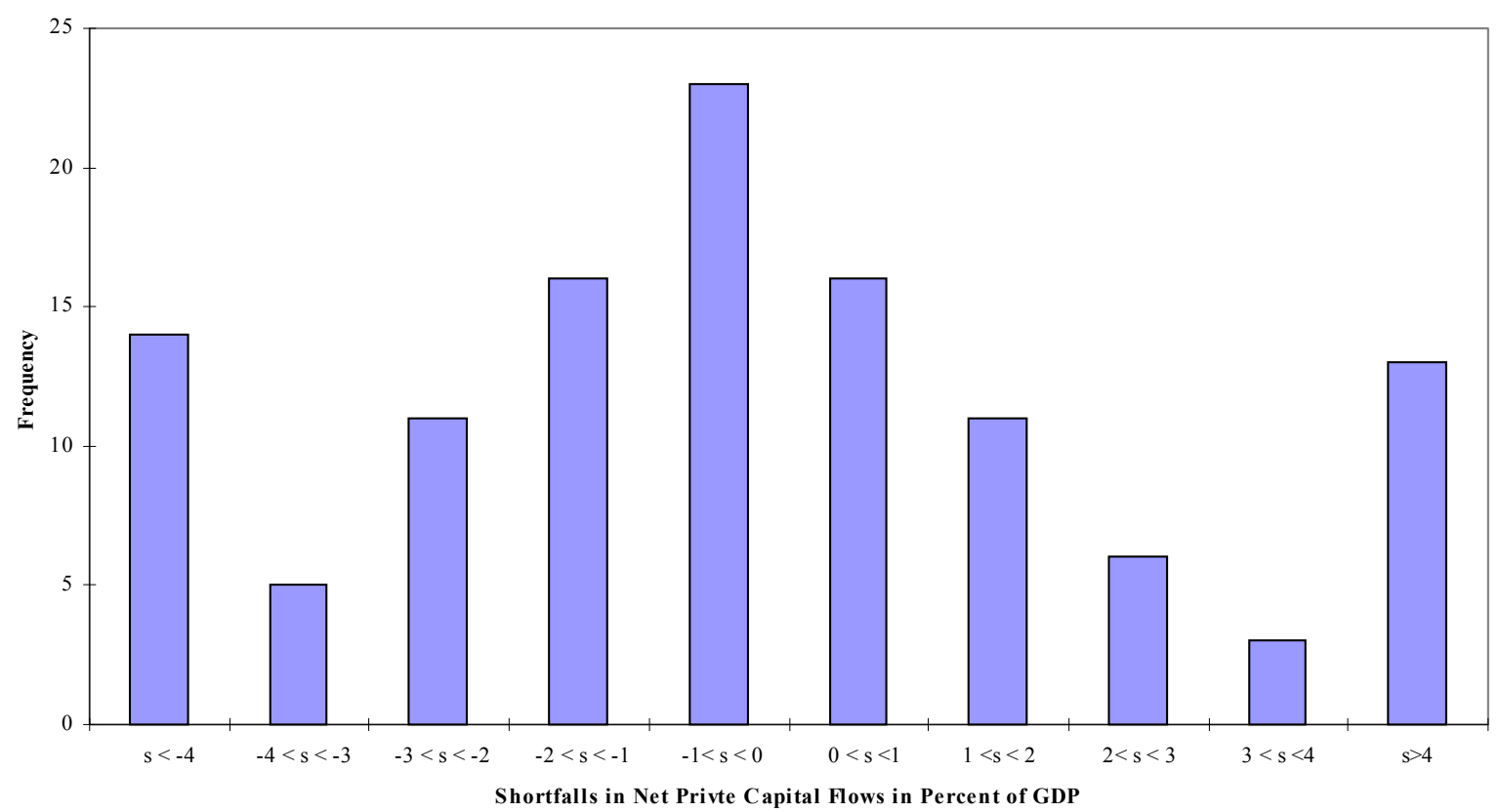

tend to be above the outcomes. The graph also shows outliers, large positive and large negative shortfalls corresponding to big failures and successes, respectively.

A characteristic that deserves particular attention is whether a program is precautionary, i.e., whether the domestic authorities state their intention not to draw the resources available under the program unless some unexpected balance of payment need arises. Indeed, there is empirical evidence that precautionary programs may be particularly suitable for conveying positive signals to private investors (see Mody and Saravia, 2003). To minimize the likelihood that the precautionary nature of a program is endogenous, my definition of "precautionary" includes only those programs that are precautionary on approval and not those that "turn precautionary" at a later stage. ${ }^{11}$ This is because turning a program into a

\footnotetext{
${ }^{11}$ Two types of programs are precautionary on approval. The first type consists of those programs that are explicitly negotiated as such. The second type consists of a smaller subset of programs that are approved as non-precautionary programs but in which the domestic authorities choose not to make the first drawing, revealing their intention of treating them as precautionary. This second type is distinct from those programs that are not precautionary on approval but turn precautionary at a later stage, which I do not treat as precautionary; there are 13 programs of this variety in my sample.
} 
precautionary one is unlikely to be an exogenous policy decision. For example, unexpected large capital inflows due to exogenous external reasons could ease the external financial constraint faced by a country, allowing it to turn its program into a precautionary one.

I identify the following stylized facts from panel A of Table 1:

- Precautionary programs project larger net private capital inflows than nonprecautionary programs do, both in terms of mean and median. This is likely to depend on the fact that precautionary programs start in relatively more tranquil times.

- In spite of being higher, the projections in precautionary programs tend to be "conservative", i.e., both the mean and median shortfall are negative - the mean shortfall is close to being statistically negative at the 10 percent confidence level. By contrast, the non-precautionary programs tend to be "right", i.e., both the mean and median shortfalls are close to zero.

- Non-precautionary programs tend to be more heterogeneous than precautionary programs, both in terms of initial projections and subsequent shortfalls (for brevity, the standard deviation of the projections is not reported).

Does a country's access to private capital markets affect how capital flows respond to a program? To measure a country's market access, I rely on the IMF World Economic Outlook (WEO)'s classification of developing, non-transition countries by main source of external financing. This classification defines three groups of countries depending on the main source of external financing: countries relying on official financing, on private financing, and on diversified financing. ${ }^{12}$ I interpret this classification as a measure of capital account openness based on the historical composition of capital inflows because countries with more open capital accounts are more likely to borrow from private sources. ${ }^{13}$ By classifying the countries into three groups that differ for their reliance on private capital, I can analyze whether there is a monotonic relationship between shortfalls in net private capital flows and reliance on private capital.

\footnotetext{
${ }^{12} \mathrm{~A}$ net debtor country is allocated to either of the first two subgroups if official sources (including official grants) or private sources (including direct and portfolio investment) account for at least two-thirds of its total external financing in the four years before the country is classified. Countries that do not meet these two criteria are classified as relying on diversified financing.

13 This notion is somewhat similar to other de facto capital account openness measures that are based on the actual behavior of capital flows; see Edison and others (2002) for a survey. Altoough not equivalent, these measures tend to replicate relatively well the measures of capital account restrictions based on de jure restrictions to capital mobility.
} 
-12 -

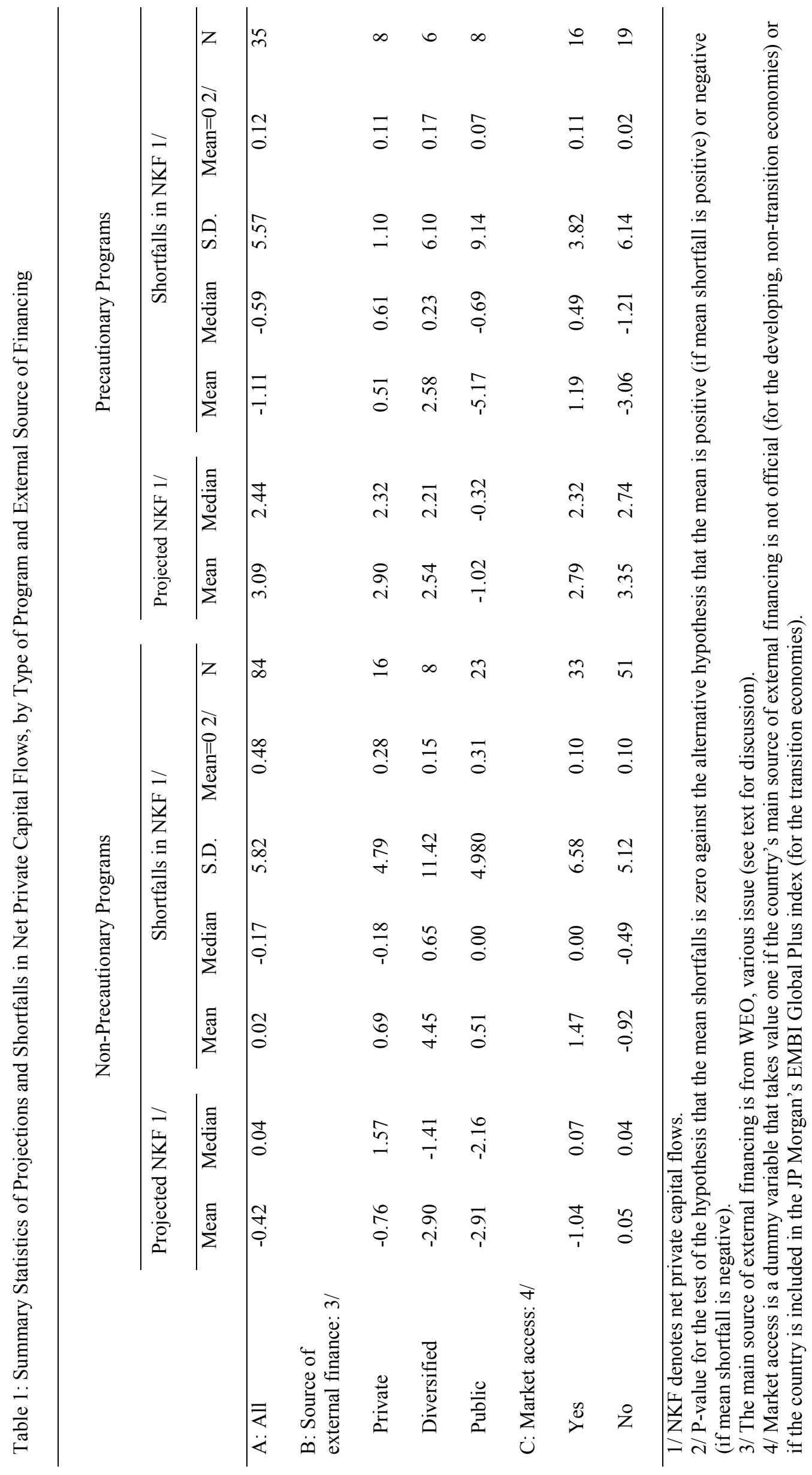


Panel B shows that relying on private sources of external financing does not necessarily lead to larger shortfalls; instead, it is the countries with diversified financing that tend to have the largest shortfalls. Although, as expected, the projected net private capital flows are larger in countries with private financing (both in terms of mean and median), the shortfalls tend to be larger in countries with diversified financing; only for precautionary programs are the median (but not the mean) shortfalls larger in countries with private financing. The average shortfalls are not, however, significantly different from zero, possibly because of the very small number of observations in each subgroup.

To include transition economies in the analysis, I construct a new dummy variable for market access by taking into account whether a transition economy is included in the JP Morgan's EMBI Global Index. Specifically, the dummy variable takes value one if a transition economy is included in this index and if a non-transition economy (classified by WEO) relies on private or diversified financing. ${ }^{14}$ Panel $\mathrm{C}$ shows that the shortfalls tend to be larger in those countries with market access (both in terms of mean and median).

\section{B. A Simple Test of Projection Efficiency}

Comparing projections of private capital flows with actual flows is interesting per se because of its implications for projection efficiency. Although statistical tests of the efficiency of forecasts are common in a variety of contexts, ${ }^{15}$ they may not be appropriate in the context of programs. Their main limitation is that they assume that the projections are unconditional optimal forecasts (in a statistical sense) of the variable being projected. Yet, program projections are conditional on the implementation of the policy adjustment negotiated between the domestic authorities and the IMF; moreover, they may themselves result from negotiations (see Musso and Phillips, 2001, and Mussa and Savastano, 1999). Other assumptions are that the same agent makes the projections and that the variable being projected is always drawn from the same distribution. The cross-country heterogeneity of economic conditions implies that these assumptions may not hold here. In spite of this, I use a simple efficiency test that is common in the literature.

Figure 2 plots actual net private capital flows in percent of GDP against their projections; the figure confirms the large variation in projections and outcomes pointed out above. However, no major bias is apparent, since actual flows are roughly distributed along the 45-degree line (the slope of the least square line is 0.91 , with an intercept of 0.28 ).

${ }^{14}$ According to this criterion, 33 nonprecautionary programs (39 percent of the total) and 16 precautionary programs (45 percent of the total) take place in countries with market access. ${ }^{15}$ See Loungani (2002) and Zitzewitz (2001) for applications to consensus forecasts and equity earning forecasts, respectively. Musso and Phillips (2001) reviews various concepts of forecast efficiency. 
Figure 2: Projected and Actual Net Private Capital Flows for All Programs

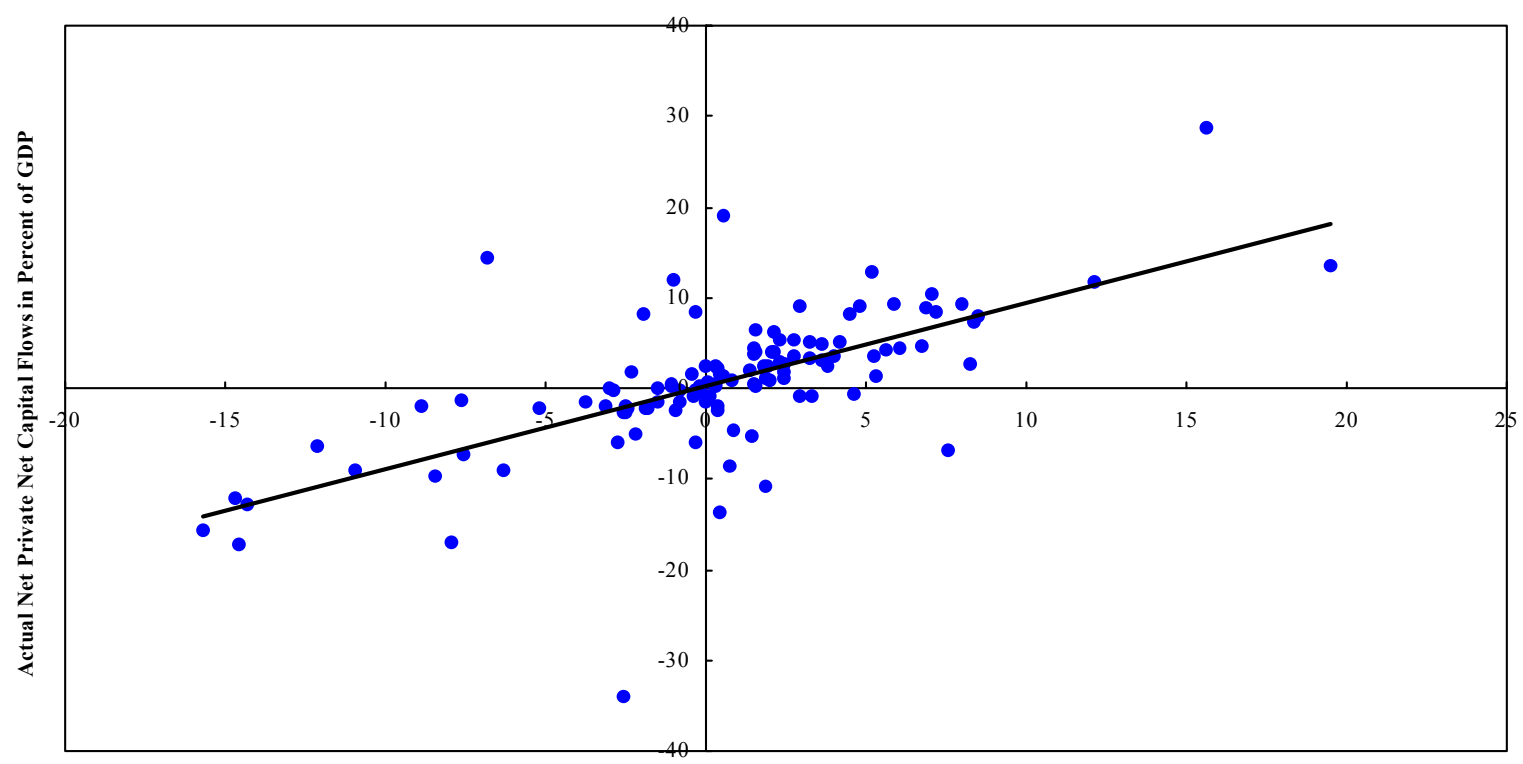

Projected Net Private Capital Flows in Percent of GDP

A formal test of projection efficiency can be based on the intuitive idea that projections should be "right on average". In other words, if projections rely on all the available information, then it should not be possible to predict systematically the projection error. For example, if the projections were on average optimistic, lowering them would eliminate the error. This implies that the projection error should not be correlated with the projection itself. In the regression of actual net private capital flows on projections,

$k=\alpha+\beta \bar{k}+u$

efficiency requires that the intercept be zero and the slope one. In column 1 of Table 2, based on the sample of all programs, the projections for net private capital flows meet the minimal efficiency requirement (this is also documented by Musso and Phillips, 2001): the slope of the equation is very close to one; although the intercept is positive, it is not statistically significant at the usual confidence levels; the joint hypothesis that the constant is zero and the slope is one cannot be rejected at the usual confidence levels.

Columns 2 and 3 carry out the test separately for precautionary and non-precautionary programs. In column 2, the test of efficiency does not reject the hypothesis that projections are efficient for non-precautionary programs. On the other hand, column 3 shows that 
Table 2: Test of Projection Efficiency

\begin{tabular}{lccc}
\hline & $(1)$ & $\begin{array}{c}(2) \\
\text { All }\end{array}$ & $\begin{array}{c}(3) \\
\text { Nonprecautionary } \\
\text { Precautionary }\end{array}$ \\
\hline & \multicolumn{3}{c}{$\begin{array}{c}\text { Dependent variable: } \\
\text { NKF in year T+1 }\end{array}$} \\
\cline { 2 - 4 } Projection & $0.918^{* * *}$ & $0.972^{* * *}$ & 0.312 \\
& $(0.103)$ & $(0.113)$ & $(0.376)$ \\
Constant & 0.280 & -0.032 & $3.180^{*}$ \\
& $(0.536)$ & $(0.641)$ & $(1.614)$ \\
R-squared & 0.428 & 0.470 & 0.048 \\
F-test for unbiased projection 1/ & 0.44 & 0.03 & 1.97 \\
Prob $>$ F & 0.644 & 0.970 & 0.155 \\
N & 119 & 84 & 35 \\
\hline Note: Robust standard errors in parenthesis. \\
1/ Test of the joint hypothesis that slope is one and constant is zero.
\end{tabular}

projections do not meet the efficiency requirement for precautionary programs: the slope coefficient is well below one (and not statistically significant from zero) and the constant is very large and statistically significant from zero at the 10 percent significance level; the test statistic of the null joint hypothesis that the slope is one and the constant is zero is close to the rejection region (the p-value is 0.155 ). However, this result may be driven by three observations corresponding to two large negative shortfalls and one large shortfall: if these observations were dropped, projections would pass the efficiency test.

For future reference, it is worth noting that the small slope coefficient found for precautionary programs implies that the shortfalls tend to grow with the magnitude of the projections; this observation will be useful below to interpret the findings on program access. $^{16}$

These tests, together with the summary statistics previously shown, suggest that the shortfalls in net private capital flows may not be truly random errors. In particular, it is worth asking whether program variables can explain them, in the following sense:

- Are the shortfalls systematically associated with program size? This question is addressed in Section IV.

${ }^{16}$ The large point estimate of the constant implies that precautionary programs with low projections for net private capital inflows tend to exhibit large negative shortfalls. 
- Can macroeconomic adjustment explain the shortfalls? Does the association between shortfalls and policy adjustment, if present, arise from the causal effect of policy adjustment on capital flows or is it due to reverse causation from capital flows to policy adjustment? This issue is studied in Section V.

\section{Does Program Size Matter?}

At a theoretical level, it is unclear whether program size affects private capital flows. On the one hand, larger programs could help attract private investors because, for example, larger programs could induce better program design and policy monitoring by improving IMF incentives (Rodrik, 1996) or because they could signal IMF confidence in a country's policies. ${ }^{17}$ Moreover, by providing foreign currency reserves that can be used to fend off a speculative attack, a larger IMF program could lower both capital outflows and the likelihood of crises (see Morris and Shin, 1998, and Corsetti et al., 2003). The effect of program size could be nonlinear because programs may need to be as large as the country's external liabilities to restore investor confidence (see Chang and Velasco, 2000) ${ }^{18}$ or because the government's optimal adjustment effort could vary in a non-monotonic fashion with program characteristics (see Morris and Shin, 2003, and Corsetti et. al. 2003). On the other hand, larger programs could simply facilitate the flight of domestic and foreign investors by providing much needed foreign currency resources. This paper addresses this ambiguity by studying the association between shortfalls in net private capital flows and program size.

A country quota, the country share in the IMF capital, constrains the amount a country can borrow under a program - program "access" in the IMF terminology. Currently, annual and cumulative limits constrain access to 100 percent and 300 percent of quota, respectively. However, the IMF Executive Board can waive these access limits in case of exceptional circumstances; starting from the end of 1997, exceptional access has been granted using a dedicated lending facility, the Supplemental Reserve Facility. ${ }^{19}$

The first data issue is to measure access itself. I measure program access as the original program access per program year, i.e., access approved at the start of the program divided by the original program maturity (in years). This definition has two advantages. First, it ensures that access is comparable to the variable of interest, shortfalls in net private capital flows in year $\mathrm{T}+1$. Second, it ensures that $\mathrm{I}$ do not treat programs with longer maturity as larger programs. This definition also implies that I do not take into account that access can change during the program — in fact, augmentations of program access are frequent, although

${ }^{17}$ Cottarelli and Giannini (2002) review the channels through which adopting an IMF program could affect the response of international investors.

${ }^{18}$ Partial bailouts may be ineffective, or even precipitate crises (see Zettelmeyer, 2000, and Jeanne and Wypslosz, 2000).

${ }^{19}$ IMF (2003a,b) review on access limits. The purpose of the Supplemental Reserve Facility is to lend to countries that face capital account pressures owing to financial contagion. 
reductions are less frequent. Since I do not include augmentations nor reductions as part of program access, I minimize the likelihood that my measure of access is endogenous. ${ }^{20}$

The second data issue arises because, to carry out a cross-program analysis, I need to scale program access. Quotas, the official IMF scaling factor for program access, may not reflect accurately the "true" country size, implying that access in percent of quotas may not accurately reflect program size. ${ }^{21}$ Therefore, I consider other scaling factors for program access. The first plausible alternative is to use a country's GDP. In particular, I use the average PPP-adjusted GDP between year T-3 and year T to prevent nominal exchange rate movements and output collapses before the program from affectting my measure of program size - although I find similar results if I use GDP in US dollars at market exchange rates. I also scale access by the stock of external liabilities at the end of year T-1 because some of the theoretical papers discussed above predict that the stock of external liabilities is the relevant measure to gauge program size.

Although quotas may not accurately reflect program size, they may still matter as scaling factor because they determine how the IMF operates as a multilateral policy institution. On the one hand, a large program in percent of quota may signal the IMF's confidence in a country's economic policies. On the other hand, large access in percent of quota may signal that the lending constraints are binding or close to being binding. In practice, these lending constraints are likely to be smaller then the official annual and cumulative access limits mentioned. The reason for this is that normally the IMF grants lower access; as a result, justifying why a specific program should have higher-than-normal-access is likely to raise the "burden of proof" on the country requesting a program.

Table 3 shows that, uniformly across the three different scaling factors, precautionary programs tend to grant lower access (in terms of mean and median) and to be more homogeneous (as measured by the standard deviation) than non-precautionary programs. ${ }^{22}$ Furthermore, mean access is larger than median access across the three scaling factors, reflecting the presence of a few very large access programs. A recent, thorough review of access in IMF programs is provided by IMF (2003a,b).

${ }^{20}$ This problem arises if, as plausible, changes in access take place in response to how private capital flows react to program characteristics. A similar problem would arise if actual disbursements or outstanding credit were used (as done by Barro and Lee, 2002). ${ }^{21}$ For example, although the programs in Korea (1997), Brazil (1998), Thailand (1997), and Indonesia (1997 and 1998) stand out as large programs in percent of quota, they are comparable to many other programs in percent of GDP.

${ }^{22}$ Table 3 excludes two non-precautionary programs in transition economies for which access in percent of external debt exceed 100 percent owing to the very low initial external debt. Including them causes the standard deviation of access in percent of external debt to jump to over 80 (from below 10) and the mean to jump to about 15 (from about 5). 
Table 3: Summary Statistics of Program Access

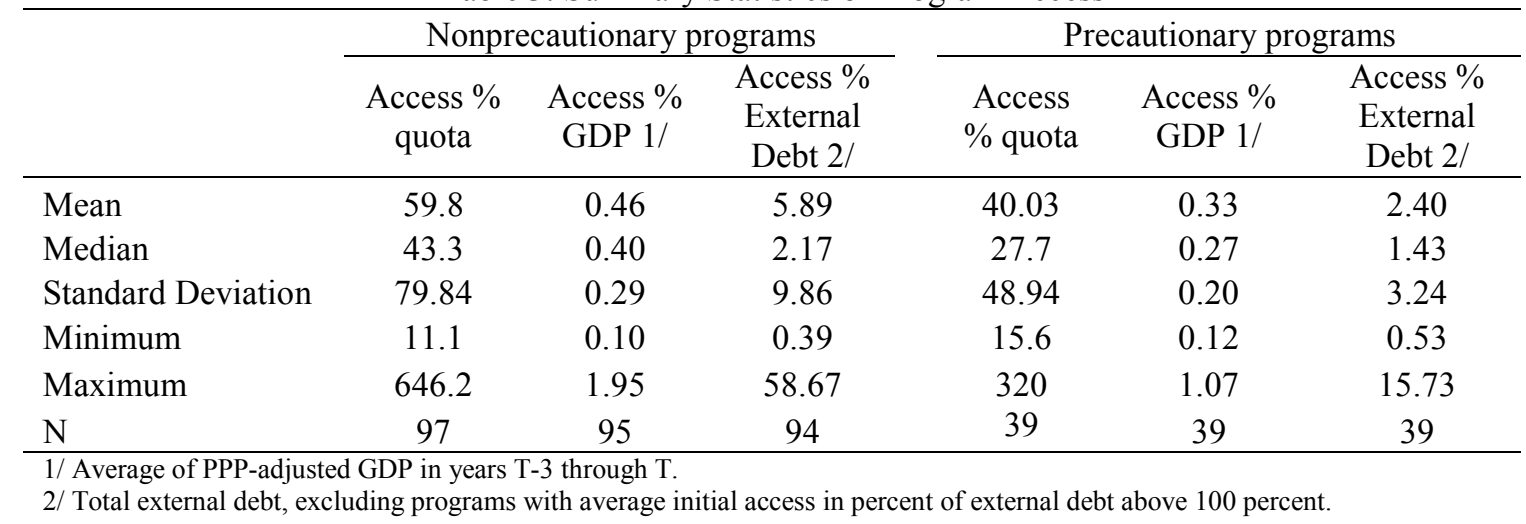

The main finding from the regression analysis in Table 4 is that program access is positively and significantly associated with the shortfalls in net private capital flows only when it is scaled by quotas. The coefficient on access in percent of quota is positive and significant for both non-precautionary and precautionary programs (see columns 1 and 8, respectively). By contrast, the other two measures of program access, access in percent of PPP-adjusted average GDP and access in percent of external debt, are not statistically significant; for both types of programs, access in percent of PPP-adjusted GDP is positively associated with the shortfalls (columns 2 and 9) while access in percent of external debt is negatively associated with them (columns 4 and 10). It is also worth pointing out that the coefficient on access in percent of quota is an order of magnitude larger for precautionary programs; it is also quantitatively non-negligible: an increase in access of ten percentage points of quota is associated with a larger shortfall of about 1.5 percent of GDP. ${ }^{23}$

Why is access in percent of quota significantly associated with the shortfalls in private flows while the other access measures are not? An explanation could be that the positive association between shortfalls and access in percent of quotas is due to institutional constraints on IMF lending. If lending constraints - expressed in percent of quotas - limit the amount that can be lent in a program, the IMF staff may be forced to generate optimistic projections for private capital inflows to "close" the financing gap that would otherwise occur. Since the pressure to generate more optimistic projections is likely to be stronger when access is large relative to quota, larger programs are likely to be associated with larger projections biases (in the direction of optimism), and therefore with larger shortfalls.

${ }^{23}$ If I drop the three outliers that imply that the projections in precautionary programs are not efficient (see Section III), then the coefficient on access in percent of quota is only three times as large for precautionary programs. 
- 19 -

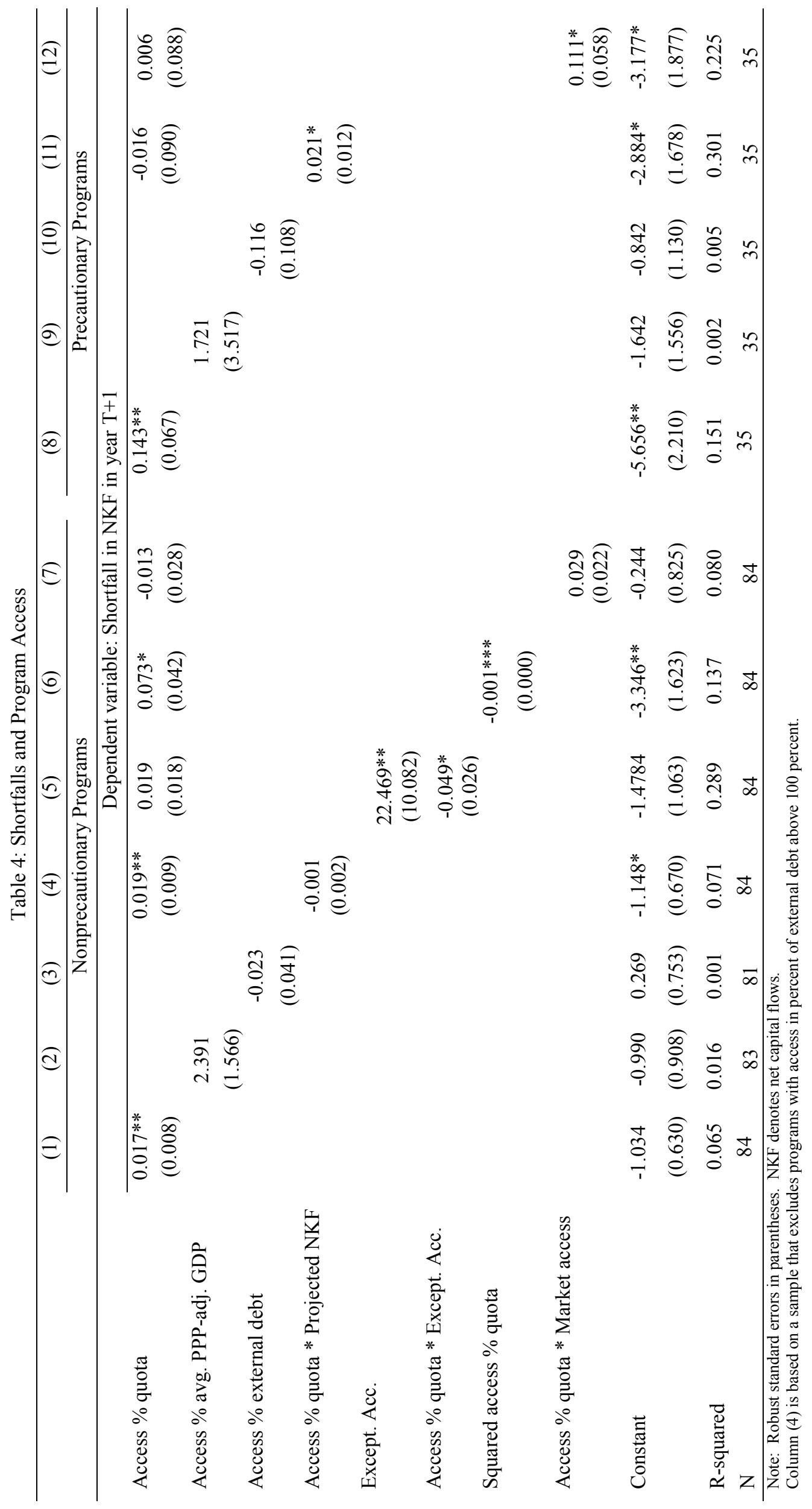


As regards precautionary programs, projection biases may indeed play a role to generate the positive association between shortfalls and program access. Column 11 provides some evidence on this by introducing an interaction term between program access and projections for net private capital flows. I would expect that, if optimistic projections substitute for program access at higher levels of access, then the positive association between shortfalls and program access should become stronger as the projections increase (because, at higher access, projections need be more optimistic). Indeed, the interaction term is positive and statistically significant and roughly accounts for the magnitude of the coefficient on access in column $8,{ }^{24}$ while the coefficient on access becomes statistically insignificant. As regards non-precautionary programs, the interaction term is fairly small and statistically insignificant (see column 4), implying that the association between program access and shortfalls may be genuinely structural, i.e., that larger programs could cause larger shortfalls.

Do exceptional access programs account for the positive association between access and shortfalls? ${ }^{25}$ Column 5 introduces a dummy variable for exceptional access and an interaction term between this dummy and program access. Interestingly, the coefficient on access in percent of quota remains very close to the estimate in column 1, but is not significant at the usual confidence levels. The dummy variable for exceptional access is large and statistically significant (at 5 percent level) — not a surprising finding given that the IMF programs during the capital account crises of the 1990s witnessed very large and unexpected net capital outflows (see Ghosh et al., 2002) - and the interaction term is negative and statistically significant (at 5 percent level). Thus, within the exceptional access programs larger programs were associated with smaller shortfalls. Although the very small number of cases does not allow general conclusions on the systematic effect of exceptional access, the largest programs do not seem to account for the positive association between program access and shortfalls documented above. Column 6 bolsters this conclusion: the quadratic term does not pick up any important nonlinearities.

Does access to private capital markets matter for the association between program access and shortfalls in net private capital flows? Columns 7 and 12 introduce an interaction term between program access and the market access dummy described in the previous section. Relative to columns 1 and 8, where the coefficient on program access does not vary with market access, the coefficient on access is smaller and statistically insignificant for both nonprecautionary (column 7) and precautionary programs (column 12). Instead, program access

24 The marginal effect of access is 0.034 when evaluated at the median program access, climbing to 0.112 when evaluated at the median plus one standard deviation of access. However, this result is not robust to outliers: the interaction term is negative but statistically insignificant if outliers are dropped.

25 There are six non-precautionary programs in the sample that granted "exceptional access" on approval: Mexico in 1995, Korea, Thailand, and Indonesia in 1997, and Brazil in 1998 and in 2001. Cases in which exceptional access was granted by augmenting existing programs are not considered here. 
has a large coefficient when interacted with the market access dummy: ${ }^{26}$ the interaction term accounts entirely for the effect of program access. In other words, the positive association between shortfalls and program access is present only in countries with market access. ${ }^{27}$

Why does program access matter only in countries with market access? An explanation could be that restricting the sample to countries with market access simply "cleans" the data by removing countries that rely mainly on official financing and thus do not provide information on how private capital flows respond to programs. Yet, countries without market access may still have significant interactions with private capital markets. For example, capital flights can take place even in countries that officially have low access to private capital markets. This finding could then mean that market access boosts the capital outflows financed by IMF-provided foreign currency reserves. This conclusion is not completely uncontroversial, since projection biases might be more likely in countries with market access because, in these countries, the constraints on IMF lending might be more likely to bind. Overall, however, it seems difficult to explain the positive association between shortfalls and program entirely as a consequence of projection biases, ${ }^{28}$ i.e., this association provides some evidence that market access tends to lower the likelihood of success.

I can summarize the findings on program access as follows:

- I have found some evidence of a positive association between shortfalls in net private capital flows and program access.

- This evidence is consistent with the hypothesis that larger programs cause private capital outflows. However, the causal interpretation of this association is ambiguous because of potential projection biases. In particular, I have found some evidence that lending constraints may force IMF staff to produce more optimistic projections at higher levels of access, which in turn implies that larger shortfalls are more likely at higher levels of access.

${ }^{26}$ The interaction term is significant at the 10 percent level only for the precautionary programs, and is very close to being significant at the 10 percent level for the nonprecautionary programs.

${ }^{27}$ Shortfalls and program access are positively associated only in countries with market access especially when I measure access in percent of external debt: the coefficient on access in percent of external debt estimated on countries with market access is positive, large, and statistically significant coefficient, and is even larger when I exclude exceptional access cases (the $\mathrm{R}$ squared coefficient climbs to over 40 percent). There is virtually no association between shortfalls and program access in the sample of countries without market access. These estimates are available upon request.

${ }^{28}$ In particular, it is hard to believe that the statistically and quantitatively strong positive association between shortfalls and program access in percent of external debt in countries with market access (see previous footnote), in which access in percent of external debt accounts up to 40 percent of the variation in shortfalls, is purely due to projection biases. 
- Exceptional access cases or failure to account for nonlinearities do not seem to account for these findings. Moreover, this association is stronger in countries with market access, i.e., market access seems to lower the probability of success (but the effect of market access is likely to be non-monotonic).

\section{How Do Capital Flows Respond to Policy Adjustment?}

How private capital flows respond to policy adjustment has received considerable attention. In this section, I assume that domestic authorities can influence capital flows by adjusting their macroeconomic policies-I do not consider here the other major dimension of policy adjustment in programs, structural adjustment. The econometric problem in estimating the causal effect of policy adjustment is that policy adjustment is endogenous, i.e., it is likely to depend on the developments in the balance of payments, and hence on capital flows. For example, tight monetary and fiscal policies may not be sustainable if a negative capital account shock causes a deep recession. The following simple system describes the feedback between policy adjustment and shortfalls in net private capital flows:

$$
\begin{aligned}
& \bar{k}-k=\beta p+\varepsilon \\
& p=\bar{p}+\eta+\lambda \varepsilon,
\end{aligned}
$$

with $E(\varepsilon)=E(\eta)=E(\varepsilon \eta)=0$. Since my purpose is to identify the portion of the shortfalls in net private capital flows due to policy adjustment, equation (3) decomposes the shortfall in net private capital flows $(\bar{k}-k)$ as sum of the effect of actual policy adjustment $(p)$ and an exogenous shock $(\varepsilon)$. This shock is a short-hand for all the factors that affect capital flows for reasons beyond the authorities' control, e.g., interest rates in industrialized countries or terms of trade changes; for simplicity, I call it a capital account shock. In equation (4), actual policy adjustment is the sum of the initial projection $(\bar{p})$, an exogenous policy shock $(\eta)$, e.g., a shock to the preferences of the domestic authorities, and a term capturing the feedback of capital account shocks on policy adjustment $(\lambda \varepsilon)$. For example, if $\lambda<0$, then a shock $\varepsilon>0$ raises the shortfall and simultaneously reduces policy adjustment. Whenever $\lambda \neq 0$, the ordinary least squares estimate of the policy parameter $\beta$ is inconsistent because policy adjustment is endogenous.

The main identifying assumption in equation (3) is that the projected policy adjustment $\bar{p}$ does not appear on the right-hand side. This exclusion restriction is based on the assumption that the IMF staff takes into account all the relevant information on what is known to affect capital flows when it formulates its projection $\bar{k}$, including, in principle, the relationship 
between the projected policy adjustment $\bar{p}$ and the projected capital flows $\bar{k} \cdot{ }^{29}$ Under this exclusion restriction and assuming that the shocks $\varepsilon$ and $\eta$ are orthogonal to the projection $\bar{p}$, the projection $\bar{p}$ is an instrument for the actual policy adjustment $p$ in (3). However, this instrument may be invalid if the projections $\bar{p}$ and $\bar{k}$ have a common bias, e.g., due to optimism in the projections; I discuss this possibility at the end of the section.

Focusing on the relationship between policy adjustment and shortfalls in net private capital flows only, as in (3), is not necessarily restrictive. This is because the shortfalls are defined relative to the initial projections for private capital flows; these should, in principle, take into account the economic conditions that led to the program. For brevity, in what follows I focus on non-precautionary programs.

\section{A. Measuring Policy Adjustment}

The first empirical problem is to measure policy adjustment in a way that is comparable across countries. Measuring the stance of economic policies is a well known problem in the literature on cross-country growth regressions, where the economic policy stance is studied as a possible determinant of economic growth (see, e.g., Fischer, 1993), and in the literature on the effects of monetary policy on speculative attacks, where the stance of monetary policy affects the likelihood of a currently attack (see, e.g., Kraay, 2003).

To measure the monetary policy stance, I would ideally use a policy instrument that is directly controlled by the monetary authorities, e.g., the discount rate charged by the central bank on the liquidity provided to the commercial banks. However, the multiplicity of policy tools and the cross-country heterogeneity of monetary policy regimes make it difficult to choose a measure of monetary policy that fits suitably all the program countries. To address this issue, some studies (for example, Kraay, 2003) have conducted robustness checks based on a variety of monetary policy measures. A simple alternative is to measure the monetary policy stance with a policy outcome, e.g., inflation. The main problem with using inflation is that it can be seen as a more general indicator of macroeconomic policy: Fischer (1993), for example, regards it as an indicator of the overall government ability to manage the economy.

I use inflation to measure monetary policy. Since programs typically require an adjustment in economic policy, I focus on the change in the end-of-period inflation rate between years $\mathrm{T}$ and $\mathrm{T}+1$, even though some policy adjustment may start before the program is formally approved (see Knight and Santaella (1997) and Mussa and Savastano (1999) on "prior actions"). Given the lags in monetary policy, the inflation rate in year $\mathrm{T}$ is unlikely to fully reflect the program-induced adjustment in monetary policy, especially for the programs

${ }^{29}$ Working with an equation in terms of shortfalls such as (3) rather than with an equation that includes the projected flows as a right-hand side determinant for actual flows is not restrictive because the coefficient on projected flows turns out to be very close to one. 
approved in the later months of the year. However, the inflation rate in year $\mathrm{T}+1$ should reflect the policy adjustment due to the program and, as a result, the change in inflation between years $\mathrm{T}$ and $\mathrm{T}+1$ should capture the monetary policy adjustment.

I use two alternative proxies for adjustment in fiscal policy, the change in overall balance and in primary balance between year $\mathrm{T}$ and year $\mathrm{T}+1$. The overall fiscal balance captures the weight of the public sector in the economy and, in particular, the demand for foreign capital originating from the public sector. However, using the overall balance has the shortcoming that interest payments are likely to depend on the supply of capital flows, implying that the overall balance may be endogenous. The primary balance does not suffer from this shortcoming; moreover, it may better capture the policy effort of domestic authorities. Below I use both measures of fiscal adjustment.

Interpreting the association between shortfalls in net capital flows and fiscal adjustment is somewhat problematic because, holding private savings constant, fiscal consolidation raises national savings and correspondingly lowers the need for external financing. If the shortfall rises more than one for one with the improvement in fiscal balance, then fiscal adjustment has "perverse" effects on capital flows because the shortfall exceeds the reduction in the demand for external financing due to the fiscal adjustment. By contrast, if the increase in the shortfall is less than one for one, then fiscal adjustment has catalytic effects. ${ }^{30}$

\section{B. Association Between Policy Adjustment and Capital Flows}

When I do not take into account that policy adjustment is endogenous, I find a positive association between the shortfalls in net private capital flows and the change in inflation, i.e., a tightening in monetary policy is associated with a lower shortfall. Column 1 of Table 5 shows that this association is statistically significant at the 5 percent confidence level but quantitatively very small: reducing inflation by 10 percentage points is associated with a smaller shortfall of only 0.02 percent of GDP.

To assess whether large changes in inflation drive this association, I estimate it by allowing the coefficient on inflation change to vary with the magnitude of inflation change. There are reasons to expect that large inflation changes may be neutral because high-inflation economies tend to develop sophisticated indexation practices; in the context of economic growth, for example, Fischer (1993) finds no relationship between inflation and growth when inflation is high. Column 2 estimates a piecewise linear function with breaks at-70 and $70 .{ }^{31} \mathrm{I}$ find that the coefficient on intermediate inflation changes is 0.083 , which is larger than the coefficients on large inflation increases and decreases, both very close to zero. Although statistically insignificant, the coefficient on intermediate inflation change is economically

30 This problem seems less severe with regared to monetary adjustment because, in contrast to fiscal policy, this effect does not arise directly from the balance of payments identity.

${ }^{31}$ I found virtually identical estimates using higher thresholds but no statistically significant results using smaller thresholds. 


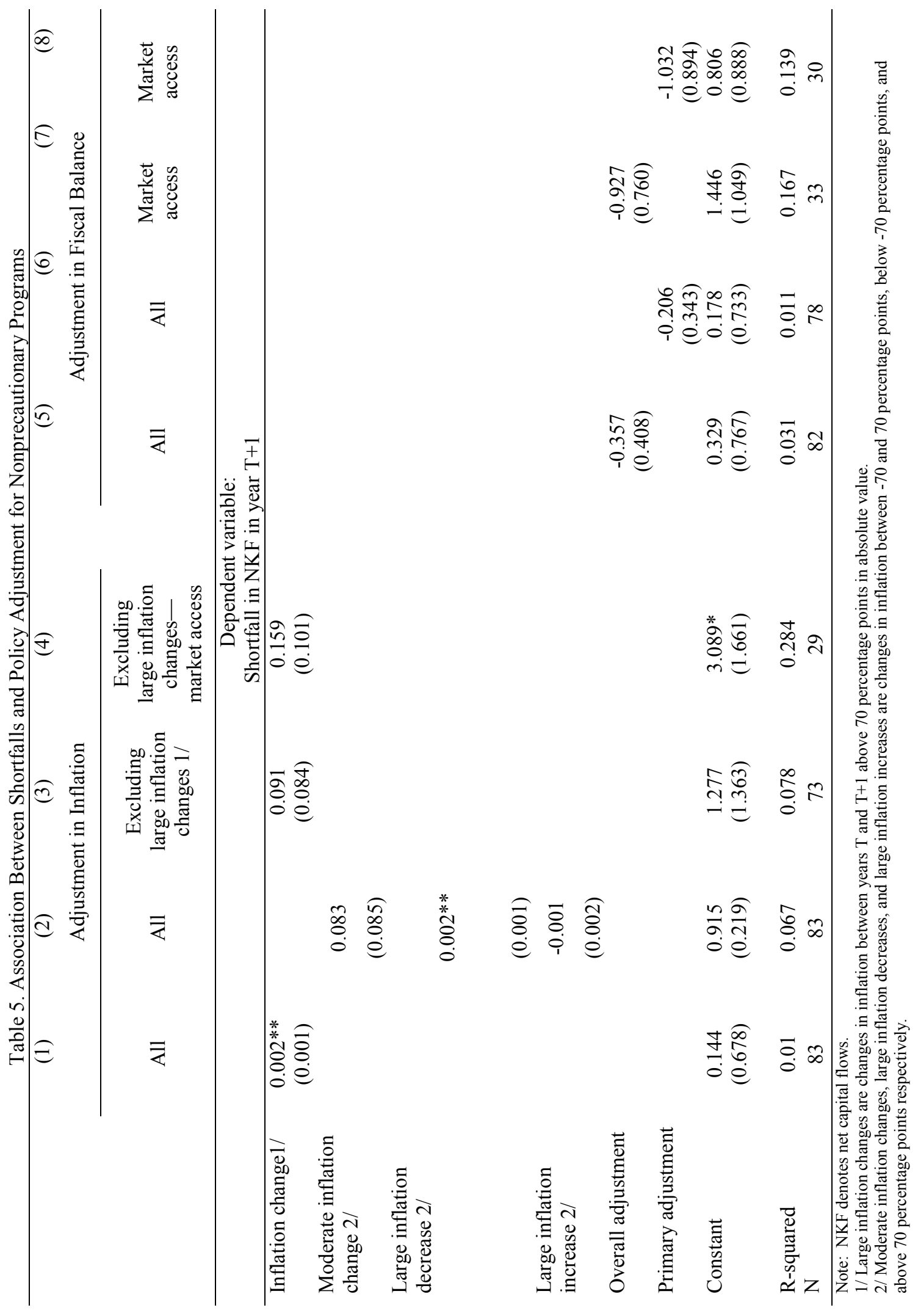


meaningful: reducing inflation by 10 percentage points is associated with a smaller shortfall of almost one percent of GDP. Column 3 finds a similar point estimate when I restrict the sample to programs with intermediate inflation changes.

If restoring investor confidence matters is critical for how capital flows respond to a program, as often argued in the literature on catalytic effects of IMF programs, then I would expect that the association between shortfalls and policy adjustment is stronger in countries with market access. Indeed, column 4 shows that this association is quantitatively stronger for these countries: the point estimate (with a p-value is 0.12 ) implies that reducing inflation by 10 percentage points is associated with a smaller shortfall of about 1.6 percent of GDP. To gauge its order of magnitude, it is worth recalling that average annual access for nonprecautionary programs is 1.6 percent of GDP. Thus, the reduction in the shortfall due to a ten percentage point fall in inflation is as large as average program access!

Concerning fiscal policy, the association between fiscal adjustment and shortfalls in net private capital flows is negative for both measures of fiscal adjustment, indicating that a larger fiscal adjustment is associated with a smaller shortfall, but statistically insignificant and quantitatively small (see columns 5 and 6 of Table 5). The point estimates imply that a fiscal adjustment of 1 percent of GDP is associated with a lower shortfall of between 0.2 and 0.4 percent of GDP. This association is statistically and quantitatively stronger in countries with market access: in columns 7 and 8, the coefficients on overall and primary adjustment are much larger (in absolute value) and close to being significant (their p-values are about 0.2 ); the R-squared coefficients are also larger. These estimates imply that improving fiscal balance by 1 percent of GDP is associated with a smaller shortfall of about 1 percent of GDP.

\section{Causal Effect of Policy Adjustment}

Although the previous findings show that policy adjustment is associated with lower shortfalls in the net private capital flows, it is not clear which way the causation runs, i.e., the association between policy adjustment and shortfalls could be the effect of exogenous capital account shocks on policy adjustment. To control for policy endogeneity, I instrument for the actual policy adjustment using the projected adjustment.

Concerning monetary policy, in (3) I instrument the actual inflation change using the projected inflation change. Table 6 reports the two-stage least square (2SLS) of equation (3). The bottom panel of Table 6 reports the first stage regressions of actual inflation change on its projection. In the countries with market access (column 2), the projections are statistically significant at the 1 level in predicting actual inflation changes and explains a large portion of its variation. The projections are less accurate in the broader subsample that includes the countries without market access (column 1). Overall, there seems to be a sufficiently strong association between projections and actual inflation changes, as shown by the large $\mathrm{R}$ squared coefficients. I discuss at the end of the section whether the second requirement of a valid instrument, i.e. that it be uncorrelated with the error term in (3), is likely to be met. 


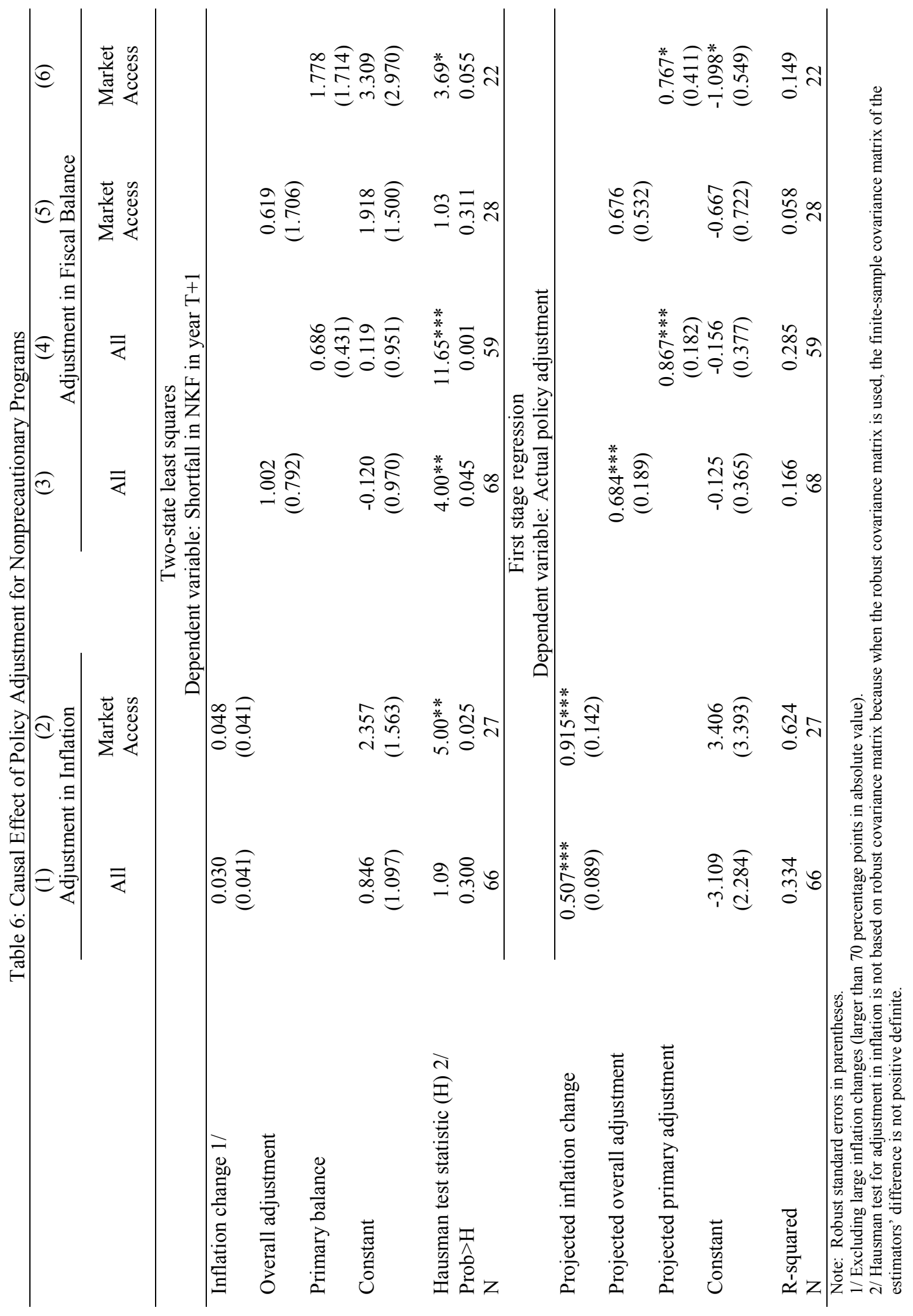


Turning to the two-least square estimates in the top panel, the Hausman test points out a statistically significant difference between the OLS and 2SLS estimates only for countries with market access, providing evidence that reverse causality is potentially important, at least in countries with market access. As expected, the 2SLS estimates of the effect of inflation change are smaller than the previous OLS estimates because the latter pick up also the effect of exogenous capital account shocks on policy adjustment. In column 1, based on all programs, the causal effect of inflation change is quantitatively small and not statistically significant. In countries with market access (column 2), the point estimate is larger, 0.048 (with a p-value of 0.26 ), but only one third of the OLS estimate. Although reverse causality explains a large portion of the association between inflation changes and shortfalls, the causal effect of policy adjustment is not quantitatively irrelevant: reducing inflation by 10 percentage points lowers the shortfall by about 0.5 percent of GDP.

Concerning fiscal adjustment, the first stage regressions show that the association between actual fiscal adjustment and its projection is not as strong as for monetary adjustment. In three out of four cases shown in Table 6, the Hausman test rejects the null hypothesis that the OLS estimates are not statistically different from the 2SLS estimates, indicating that the endogeneity bias in the OLS estimates is potentially important. This result is not surprising given that all the 2SLS point estimates of the coefficient on fiscal adjustment in the top panel of Table 6 have a different sign relative to the OLS estimates in Table 5. However, these estimates are not significant at the usual confidence levels-but in column 2 the estimate is close to being significant at the 10 percent, the p-value is 0.11 . Only for primary adjustment in countries with market access (column 4) is the coefficient larger than one, which, according to the previous interpretation, indicates "perverse" effects of fiscal adjustment.

To summarize, these findings show that the association between shortfalls in net private capital flows and inflation change is not merely the result of reverse causation from capital flows to policy adjustment. This evidence is consistent with the hypothesis that, in countries with market access, tight monetary policy helps stimulate private capital inflows (as claimed by Rogoff, 2003). On the other hand, there is no evidence that fiscal adjustment has either systematic catalytic or perverse effects. The negative association between fiscal adjustment and shortfall in net private capital flows found in Table 5 thus appears to be due to the reverse causation of capital account shocks on policy adjustment. Given the poor statistical precision of the estimates, though, caution should be used in interpreting these findings.

Estimating the causal effects of policy adjustment relies on assuming that the projected policy adjustment is a valid instrument for the actual adjustment. However, since program projections are also used to define the shortfalls in net private capital flows, the projections for policy adjustment could be correlated with the shocks to the shortfalls in (3) if there is a common bias in the projections. In Appendix I, I attempt to quantify the potential bias that can result from projection biases. Intuitively, I use the deviations from the efficiency concept introduced in Section III to construct measures of projections biases. I use these measures to estimate the correlations between instruments and the shocks in the shortfalls, which in turn allow me to quantify the bias in the 2SLS estimates due to invalid instruments. The bias turns 
out to be two orders of magnitude smaller than the 2SLS estimates. Thus, I do not detect important problems with this identification strategy.

\section{CONCLUding ReMARKS}

In this paper, I have defined a program to be successful if the program projections for net private capital flows are met or exceeded. Starting from the premise that a program consists of financial assistance and policy adjustment, I have focused on the size of financial assistance (the "program size") and policy adjustment as determinants of program success. This approach has several advantages: it avoids the thorny issue of defining counterfactual scenarios; it allows me to control for the fact that programs differ in the mix of policy adjustment and financing that they prescribe; and it allows me to estimate the causal effect of policy adjustment. Although data quality hampers the statistical precision of some of the findings, the empirical evidence seems to depict a consistent picture of the effects of IMF programs on private capital flows.

The first main finding is that program success is not purely a random event. In particular, success is negatively associated with the size of financial assistance, especially in those countries with access to private capital markets. This empirical association is difficult to interpret unambiguously: it could mean that larger programs facilitate capital outflows, but it could also mean that the IMF often hits a binding lending constraint on the size of its lending. In fact, I have found some evidence that the negative association between success and program size could arise from projection biases. These biases, in turn, seem to arise from the fact that the pressure on IMF staff to generate optimistic projections in response to binding lending constraints is likely to be stronger in larger programs.

The second main finding is that policy adjustment - more in monetary policy than in fiscal policy - seems to contribute to program success, especially in countries with market access. Although the causal effect of policy adjustment is not estimated precisely, the estimates are smaller when controlling for policy endogeneity. This suggests that exogenous capital account shocks are important determinants of what policy adjustment the domestic authorities undertake, especially in countries with market access. 


\section{Consequences of Biased Projections for Instrument Validity}

Using the program's projections as instruments for the actual policy adjustment can lead to inconsistent 2SLS estimates if the projections of net private capital flows and the projections of the policy variables contain a common bias, for example, because of problems in the underlying model that is used to formulate such projections. I show now how it is possible to quantify this bias.

Let $\widetilde{k}$ and $\widetilde{p}$ denote the projections of net capital flows $k$ and of the policy adjustment $p$, e.g., the change in inflation under the program. Suppose that $\tilde{k}$ and $\widetilde{p}$ are biased projections, in the sense that they differ from the "true" (unobserved) projections $\bar{k}$ and $\bar{p}$ by the biases $k_{b}$ and $p_{b}$ respectively, i.e., $\widetilde{k}=\bar{k}+k_{b}$ and $\tilde{p}=\bar{p}+p_{b}$. The unobserved projections $\bar{k}$ and $\bar{p}$ are the conditional expectations using all the available information. The structural estimation strategy is based on estimating the following equation,

$$
\widetilde{k}-k=\beta p+\eta
$$

using the projection $\tilde{p}$ as an instrument for $p$. Using (4), it is possible to write the error term in the estimated equation (5) as $\eta=\varepsilon+k_{b}$, which is correlated with the instrument- the biased projection $\tilde{p}$-as long as the projection biases are correlated, since $\operatorname{Cov}(\tilde{p}, \eta)=\operatorname{Cov}\left(p_{b}, k_{b}\right)$. Thus, the sign of the correlation between the projection biases $k_{b}$ and $p_{b}$ yields the sign of the bias in the 2SLS estimate of $\beta$ that uses $\tilde{p}$ to instrument for $p$. For example, if the biases in the projections are negatively correlated because both projections are too optimistic - inflation is expected to be too low and capital flows too large - then the estimation procedure introduces a downward bias in the estimate of the parameter $\beta$. The following procedure presents a simple procedure that attempts to quantify this bias.

Regress the actual outcome of net capital flows $k$ on the available projection $\tilde{k}$, and denote by $\hat{\alpha}$ and $\hat{\beta}$ the OLS estimates of the constant and slope, and by $\hat{u}$ the residuals of this regression. If the projections were unbiased, then the constant should be zero and the coefficient on the projection should be one. Therefore, a measure of the projection bias $k_{b}$ can be constructed as $\hat{k}_{b}=\hat{\alpha}+(\hat{\beta}-1) \tilde{k}$. This quantity is what should be added to the actual projection $\widetilde{k}$ to make it an unbiased projection, in the sense that it differs by the actual realization $k$ by a zero mean error (the residual $\hat{u}$ ). Note that if $\widetilde{k}$ is unbiased, i.e., $\hat{\alpha}=0$ and $\hat{\beta}=1$, then $\hat{k}_{b}=0$. A measure $\hat{p}_{b}$ of the projection bias $p_{b}$ is constructed is a similar way. 
Regress $\hat{k}_{b}$ on $\hat{p}_{b}$ to compute the OLS coefficient $\beta_{B}$.

It is possible to express the bias in the 2SLS estimate of the structural effect of the policy as follows:

$$
\operatorname{Bias}=\frac{\operatorname{Cov}\left(p_{b}, k_{b}\right)}{\operatorname{Cov}(p, \widetilde{p})}=\frac{\operatorname{Cov}\left(p_{b}, k_{b}\right)}{V\left(p_{b}\right)} \frac{V(\widetilde{p})}{\operatorname{Cov}(p, \widetilde{p})} \frac{V\left(p_{b}\right)}{V(\widetilde{p})}=\frac{\beta_{B}}{\beta_{1}} \frac{V\left(p_{b}\right)}{V(\widetilde{p})}
$$

where $\beta_{1}$ is the OLS coefficient in the first stage regression of the 2SLS procedure.

Table A. 1 reports the biases resulting from this computation (column 5) together with the 2SLS estimates that are potentially affected by the bias (in column 6, from Tables 13). The implied biases in the structural estimates reported in column 5 are roughly two orders of magnitude smaller than the structural point estimates reported in column 6 , and thus do not affect the overall thrust of the previous findings.

Table A.1: Bias in Structural Estimates Owing to Projection Biases

\begin{tabular}{lcccccc}
\hline & $(1)$ & $(2)$ & $(3)$ & $(4)$ & $(5)$ & $(6)$ \\
Policy measure $(x)$ & $\beta_{B}$ & $\beta_{1}$ & $V\left(x_{b}\right)$ & $V(\tilde{x})$ & Bias & $\begin{array}{c}\text { Structural } \\
\text { Coefficient }\end{array}$ \\
\hline Inflation change 1/ & & & & & & \\
Overall adjustment & 0.0009 & 0.507 & 78.004 & 334.556 & 0.0004 & 0.030 \\
Primary adjustment & -0.0097 & 0.666 & .366 & 3.273 & -0.0016 & 1.002 \\
\hline
\end{tabular}

1/ Excluding large inflation changes. 


\section{REFERENCES}

Barro, Robert J., and Jong-Wha Lee, 2002, "IMF Programs: Who Is Chosen and What Are the Effects?, NBER Working Paper No. 8951 (Cambridge, Massachusetts: National Bureau of Economic Research).

Basurto, Gabriela, and Atish R. Ghosh, 2000, "The Interest Rate-Exchange Rate Nexus in the Asian Crisis Countries", IMF Working Paper 00/19 (Washington: International Monetary Fund).

Berg, Andrew, Eduardo Borenzstein, Ratna Sahay, and Jeronim Zettelmeyer, 1999, "The Evolution of Output in Transition Economies: Explaining the Differences", IMF Working Paper 99/73 (Washington: International Monetary Fund).

Bird, Graham, and Dane Rowlands, 1997, "The Catalytic Effects of Lending by the International Financial Institutions", World Economy 20, 2, pp. 955-975.

—, "IMF Lending: How Is It Affected By Economic, Political and Institutional Factors?," Policy Reform 4, pp. 243-270.

— 2002, "Do IMF Programmes Have a Catalytic Effect on Other International Capital Flows?", Oxford Development Studies 30, 3, pp.229-249.

Bulír, Aleš, and Soohin Moon, 2003, "Do IMF-Supported Programs Help Make Fiscal Adjustment More Durable?”, IMF Working Paper 03/38 (Washington: International Monetary Fund).

Chang, Robert, and Andres Velasco, 2000, "Liquidity Crises in Emerging Markets: Theory and Policy", NBER Macroeconomics Annual 1999, edited by Ben S. Bernanke and Julio Rotemberg (Cambridge, MA: MIT Press).

Corsetti, Giancarlo, Bernardo Guimaraes, and Nouriel Roubini, 2003, "The Trade-Off between an International Lender of Last Resort to Deal with Liquidity Crises and Moral Hazard Distorsions. A Model of the IMF's Catalytic Finance Effect", unpublished.

Cottarelli, Carlo, and Curzio Giannini, 2002, "Bedfellows, Hostages, or Perfect Strangers? Global Capital Markets and the Catalytic Effect of IMF Crisis Lending”, IMF Working Paper 02/193 (Washington: International Monetary Fund).

Dell'Ariccia, Giovanni, Isable Schnabel, and Jeromin Zettelmeyer, 2002, "Moral Hazard and International Crisis Lending: A Test”, IMF Working Paper 02/181 (Washington: International Monetary Fund). 
Dicks-Mireaux, Louis, Mauro Mecagni, and Susan Schadler, 2000, "Evaluating the Effect of IMF Lending to Low-Income Countries", Journal of Development Economics, 61, April, pp. 495-525.

Edison, Hali, Michal Klein, Luca Ricci, and Torsten M. Slok, 2002, “Capital Account Liberalization and Economic Performance: Survey and Synthesis", IMF Working Paper 02/120 (Washington: International Monetary Fund).

Edwards, Martin S., 2000, "Reevaluating the Catalytic Effects of IMF Programs", paper for presentation at the Annual Meetings of the American Political Science Association, Washington, DC (September).

Eichengreen, Barry, and Ashoka Mody, 2001, "Bail-Ins, Bailouts, and Borrowing Costs", IMF Staff Papers 47, 2001, pp. 155-187.

Fischer, Stanley, 1993, “The Role of Macroeconomic Factors in Growth”, Journal of Monetary Economics 32, 1993, pp. 485-512.

Furman, Jason, and Joseph E. Stiglitz, 1998, "Economic Crises: Evidence and Insight from East Asia", Brooking Papers on Economic Activity, 2, pp. 1-135.

Ghosh, Atish, Timothy Lane, Marianne Schulze-Ghattas, Aleš Bulíř, Javier Harmann, and Alex Mourmouras, 2002, "IMF-Supported Programs in Capital Account Crises", IMF Occasional Paper 210.

Haque, Nadeem U1, and Mohsin S. Khan, 1998, "Do IMF-Supported Programs Work? A Survey of the Cross-Country Empirical Evidence”, IMF Working Paper 981/69 (Washington: International Monetary Fund).

International Monetary Fund, 1993, Balance of Payments Manual, Fifth Edition, Washington, DC.

_ 2003a "Review of Access Policy Under the Credit Tranches and the Extended Fund Facility", http://www.imf.org/external/np/tre/access/2003/011403a.htm.

— 2003b, "Access Policy in Capital Account Crises-Modifications to the Supplemental Reserve Facility (SRF) and Follow-Up Issues Related to Exceptional Access Policy", http://www.imf.org/external/np/tre/access/2003/pdf/011403.pdf.

Knight, Malcolm, and Julio A. Santaella, 1997, "Economic Determinants of IMF Financial Arrangements", Journal of Development Economics 54, pp. 405-436.

Kraay, Aart, 2003, “Do High Interest Rates Defend Currencies During Speculative Attacks?", Journal of International Economics 59, pp. 297-321. 
Krueger, Anne O., 1998, “Whither the World Bank and the IMF?”, Journal of Economic Literature XXXVI, December, pp. 1983-2020.

Marchesi, Silvia, 2003, “Adoption of an IMF Programme and Debt Rescheduling. An Empirical Analysis”, Journal of Development Economics 70, pp. 403-423.

Mody, Ashoka, and Diego Saravia, 2003, "Catalyzing Capital Flows: Do IMF Programs Work as Commitment Devices?”, IMF Working Paper 031/00 (Washington: International Monetary Fund).

Morris, Stephen, and Hyun Song Shin, 1998, "Unique Equilibrium in a Model of SelfFulfilling Currency Attacks”, American Economic Review 88, 3, pp. 587-597.

—_, 2003, “Catalytic Finance: When Does It Work?”, Unpublished, Yale University.

Mussa, Michael and Miguel Savastano, 1999, "The IMF Approach to Economic Stabilization", IMF Working Paper 99/104 (Washington: International Monetary Fund).

Musso, Alberto, and Steven Phillips, 2001, "Comparing Projections and Outcomes of IMF-Supported Programs”, IMF Working Paper 01/45 (Washington: International Monetary Fund).

Przeworski, Adam, and James Raymond Vreeland, 2002, "The Effect of IMF Programs On Economic Growth”, Journal of Development Economics 62, 2, pp. 385-421.

Ramcharan, Rodney 2003, “Assessing IMF Programs Effectiveness”, IMF Research Bulletin 4, 2, June.

Rodrik, Dani, 1996, "Why Is There Multilateral Lending?" in Annual World Bank Conference on Development Economics 1995 (eds. M. Bruno and B. Pleskovic), April.

Rogoff, Kenneth, 2003, “The IMF Strikes Back”, Foreign Policy 134, January/February.

Zettelmeyer, Jeromin, 2000, "Can Official Crisis Lending be Counterproductive in the Short Run?”, Economic Notes, 2000, Vol. 29, No. 1, pp. 13-29

Zitzewitz, Eric, 2001, "Measuring Herding and Exaggeration by Equity Analysts and Other Opinion Sellers", Unpublished, Stanford University. 